

\section{ARQUITETURA PAISAGÍSTICA CONTEMPORÂNEA NO BRASIL}

FARAH, Ivete; BAHIA, Mônica Schlee; TARDIN, Raquel (Orgs.)

São Paulo: Senac, 2010

\section{UM AGRADÁVEL PASSEIO PELOS JARDINS BRASILEIROS}

\section{Sérgio Treitler}

Nos anos 70, ainda estudante de arquitetura e estagiário do escritório de Roberto Burle Marx, não era muito fácil encontrar livros sobre paisagismo, muito menos os que abordassem a arquitetura paisagística. Sem querer traçar aqui uma linha do tempo das publicações sobre paisagismo, cabe registrar que houve um período em que existia apenas alguns poucos títulos importados, a maioria deles voltados muito mais para a jardinagem do que para o paisagismo. Henrique Mindlin havia lançado, em 1956, Modern architecture in Brazil, que só seria traduzido para o português em 1999, dedicando o último capítulo do livro ao nosso paisagismo. Mindlin reservou sete páginas, entre quase 300, para nosso paisagismo, no qual o foco principal já incidia sobre a obra de Burle Marx, com seis páginas a ele dedicadas, e uma única página dedicada a três projetos do paisagista Carlos Perry.

Pietro Maria Bardi, com seu The tropical gardens of Burle Marx, de 1964, seria pioneiro em tratar a obra de Burle Marx isoladamente, sendo seguido, praticamente, duas décadas depois, por Flávio Motta, com seu Roberto Burle Marx e a nova visão da paisagem, de 1983. Seguiu-se outro período sem publicações de destaque, ressalvando-se os textos sobre paisagismo dos Cadernos brasileiros de arquitetura, com dois volumes dedicados ao nosso paisagismo. Foi um período em que a menção ao nosso paisagismo aparecia apenas nos livros que abordavam a arquitetura moderna brasileira, detendo-se quase sempre sobre a obra de Burle Marx.

No final dos anos 80, muito do que vinha lá de fora também se debruçava sobre a produção arquitetônica e as intervenções urbanas, referindo-se aos jardins apenas como mero complemento. Em uma época na qual adquirir uma publicação estrangeira era uma tarefa difícil, cara e demorada, o que salvava é que livros como o de Pietro Maria Bardi e outros como Design with nature, de lan MacHarg (1969), The gardens of Roberto Burle Marx, de Sima Eliovson (1981) e Cities, de Lawrence Halprin (1972), podiam ser lidos no escritório de Burle Marx.

Na década de 1990 o foco das editoras continuou sendo a vida e a obra de Burle Marx, temas sempre muito bem-vindos, mas não supriam a carência de obras que tratassem nosso paisagismo com uma ótica mais ampla. Encontravam-se livros sobre Lawrence Halprin ou sobre o que estava sendo feito em Barcelona com mais facilidade do que um que abordasse nossa produção paisagística. 
Na virada dos anos 90 para 2000 veio a coleção Quadro do Paisagismo no Brasil, tendo Silvio Soares Macedo à frente, trabalho que seria complementado com outros dois títulos: Parques urbanos no Brasil (Macedo e Francine Sakata) e Praças brasileiras (Fabio Robba e Macedo), todos com bons textos opinativos, que viraram fonte de consulta indispensável aos que se debruçam sobre o tema da arquitetura paisagística.

A primeira década de 2000 foi pródiga na publicação de livros sobre arquitetura paisagística, mas a exemplo das décadas anteriores, o assunto era quase sempre Burle Marx, sua vida e obra. Mas o conteúdo dos livros sobre arquitetura paisagística começaria a mudar. Eduardo Barra, Benedito Abbud, Rosa Kliass - que também abordou a questão da formação profissional do arquiteto paisagista, além de outros profissionais atuantes e por isso mesmo com experiência prática sobre o tema, extrapolando e acrescentando uma nova visão aos relatos antes contidos nos limites da pesquisa acadêmica, finalmente colocariam no papel novas idéias, novas formas de ver e entender o jardim e a paisagem, tornando acessíveis seus pensamentos e vivências profissionais no campo da arquitetura paisagística.

A partir daí, além de termos acesso aos livros que discorriam sobre a obra de Burle Marx, também tínhamos acesso às idéias de diferentes profissionais, principalmente daqueles que defendiam o pão de cada dia fazendo projetos. Nessa nova leva de livros encontra-se o indispensável Paisagismo e ecogênese, de Fernando Chacel, cuja linguagem acessível, quase didática, propicia-nos uma boa visão sobre seu pensamento sobre ecologia, paisagismo e paisagem. Seguindo nessa esteira de visões diferenciadas, José Tabacow reeditou as palestras de Burle Marx na segunda edição de Roberto Burle Marx: Arte \& paisagem, trazendo um novo olhar sobre o pensamento do mestre, comentando as palestras por ele proferidas em diferentes momentos e contextos com a propriedade de quem conviveu estreitamente com ele, ajudou-o a transformar pensamento em texto, a colocar no papel os conceitos e as idéias que Roberto defendia.

No ano de 2008, assim como o de 2009, quando se comemorou o centenário de Burle Marx, foram muitos os livros sobre sua obra, que abordaram desde as receitas culinárias oferecidas aos amigos nos concorridos almoços de domingo, passando pela publicação de trabalhos como Modernidade verde - Jardins de Burle Marx, de Guilherme Mazza Dourado, indo até ao caprichadíssimo - em forma e conteúdo, catálogo da exposição 100 anos de Burle Marx - A permanência do instável, consolidando a preferência dos pesquisadores, editores e patrocinadores sobre a vida e a obra de Roberto.

E agora, enfim, chega-nos algo novo. Arquitetura paisagística contemporânea no Brasil é um livro cuja abordagem, como não poderia deixar de ser, também tem na obra de Burle Marx seu eixo condutor, mas que não se detém apenas nela. Pelo contrário: usa a obra de Roberto como referência para, a partir dela, situar outras obras, de outros paisagistas, inclusive abordando projetos situados fora do eixo Rio - São Paulo, que predominaram em outros trabalhos sobre a arquitetura paisagística brasileira até então. 
Arquitetura paisagística contemporânea no Brasil já define sua proposta no título: analisar nossa produção paisagística contemporânea. E seu conteúdo também não se restringe só a isso, pois à medida que analisa diferentes fases do desenvolvimento da arte de projetar paisagens, paralelamente nos traz a história da evolução da Associação Brasileira de Arquitetos Paisagistas - ABAP, criada em 1976 e cuja história se confunde com a história e com a evolução da arquitetura paisagística brasileira.

O primeiro capítulo do livro, que analisa nosso paisagismo de seus primórdios até a década de 1930, foi entregue a Hugo Segawa, que aborda a evolução de nosso paisagismo à luz da história do paisagismo. Segawa discorre sobre uma parte de nossa história dos jardins pouco tratada pelos estudiosos do assunto - a presença de Maurício de Nassau em Recife e Olinda, e aborda a construção do passeio público carioca com o conhecimento de causa de quem já havia se debruçado sobre esse tema em seu livro Ao amor do público - Jardins no Brasil, de 1996, infelizmente esgotado.

Na passagem do século 19 para o 20 seu texto chama a atenção para a questão da higienização das cidades, e destaca a obra pioneira de Antônio José de Lemos, no Pará, quando foram criadas praças, parques e realizada a arborização das novas avenidas e da área central da cidade, trabalho executado por Eduardo Hass, então diretor do Serviço de Bosques, Parques, Jardins e Hortos Municipais de Belém. E a obra de Lemos e Hass é importante porque a ênfase sobre a reurbanização das cidades na virada do século recaem, quase sempre, sobre as obras de Pereira Passos, no Rio de Janeiro.

Analisa a obra de Glaziou no Rio de Janeiro, a atuação de seu discípulo Paul Villon em Belo Horizonte e as propostas de Joseph-Antoine Bouvard para São Paulo. Comenta a vinda de Barry Parker, que nos trouxe o conceito de garden city, de Ebenezer Howard, criando o bairro dos Jardins, em São Paulo, e partindo daí faz uma ligação com o trabalho de Attilio Correia Lima em Goiânia, que também seguiu o conceito de cidade-jardim e o do city beauty, com suas largas avenidas e parques fartamente arborizados, até chegar com nosso paisagismo ao final da década de 1930.

No segundo capítulo, Ana Rita Sá Carneiro nos leva até 1976 e inicia seu ensaio comentando a visão que começava a tomar conta do panorama artístico brasileiro, como desdobramento da Semana de 22, desembocando na formação da corrente modernista brasileira, para então entrar na atuação de Burle Marx em Recife, entre 1934 e 1937, quando exerceu o cargo de diretor do Setor de Parques e Jardins da cidade, atuando em reformas e novos projetos para os jardins públicos da cidade.

Em Recife, Burle Marx pode por em prática sua visão inovadora de paisagismo, utilizando espécies nativas brasileiras, até então vistas como "mato", dispostas sobre um desenho absolutamente novo, resultado da visão artística que Burle Marx carregava em sua bagagem, consolidando, com seus projetos, o jardim moderno brasileiro, onde desenho e vegetação tinham o mesmo peso no resultado alcançado. Nosso paisagismo começava, em Recife, a deixar para trás as influências européias, adquirindo personalidade própria.

Isso iria influir diretamente, nos anos 50, na obra de outros paisagistas, como José da Silva Azevedo Neto - cuja obra magistral veio a público apenas recentemente, em 
2006, por meio de uma belíssima exposição realizada pela Fundação de Parques e Jardins do Rio de Janeiro, Luiz Emygdio de Mello Filho, colaborador de Roberto em importantes projetos, inclusive no Aterro do Flamengo e Roberto Cardozo, em São Paulo.

Artista múltiplo, recém-chegado da Europa, onde havia tido contato com o melhor da produção artística internacional, Burle Marx se alimentava de seus experimentos artísticos, que transpunha para os jardins e vice-versa, iniciando, assim, uma carreira singular. $\bigcirc$ conhecimento sobre a flora local viria por meio de incursões pelo interior do estado, coletando, observando e buscando entender cada vez mais a característica e a possibilidade de uso paisagístico de várias espécies. Roberto utilizaria também árvores e espécies aquáticas da região amazônica, como na praça da Casa Forte e espécies do cerrado, como as cactáceas da praça Euclides da Cunha, aplicando a coerência ecológica em seus projetos, característica que acompanharia suas obras até o final de sua produção e influenciaria tantos outros paisagistas.

Encontra-se em curso, no Iphan de Recife, um processo, já em fase conclusiva, recomendando ao Conselho Consultivo da instituição o tombamento da obra paisagística de Burle Marx em Recife. Trabalho que começou na Universidade Federal de Pernambuco, coordenado por Ana Rita Sá Carneiro e que engloba as praças da Casa Forte, Euclides da Cunha, do Derby e Salgado Filho e o jardim do Palácio das Princesas, recomendação que, se aprovada pelo Conselho, perpetuará a obra de Burle Marx em Recife.

Na fase seguinte a Recife, o texto destaca o jardim terraço do hoje Palácio Gustavo Capanema, o "prédio do MEC", jardins como os do conjunto da Pampulha e do Cassino de Araxá, além dos jardins particulares, como os das residências Odete Monteiro e Edmundo Cavanellas, ambas em Petrópolis. Também comenta a aquisição do Sítio Santo Antonio da Bica, em Guaratiba, hoje Sítio Roberto Burle Marx, e seu significado para Roberto, que teria nele seu cadinho, em que seus experimentos botânicos podiam ser postos em prática e que hoje está sob a responsabilidade do Iphan.

Do Parque Del Leste, do final dos anos 50, o texto passa para o Aterro do Flamengo, na década de 1960, e aborda a vasta obra de Roberto pelo Brasil até os anos de 1990, com destaque para o desenho do Calçadão de Copacabana, que se tornou símbolo da cidade do Rio de Janeiro tanto quanto o Pão de Açúcar e o Corcovado.

E o texto entra, então, em um outro universo, desviando o foco da magistral obra de Burle Marx para a de outros paisagistas, não menos criativos e importantes: Azevedo Neto, Luis Emygdio, Roberto Cardozo, Fernando Chacel, Rosa Kliass, Miranda Magnoli e tantos outros. É a época do surgimento de outros escritórios de paisagismo pelo Brasil, que contribuíram para elevar ainda mais o nível de nosso paisagismo.

O terceiro capítulo é assinado por Ivete Farah e analisa nossa produção paisagística entre os anos de 1976 a 1985. É nesse período que a visão de preservação e o conceito de ecologia se consolidam e é o momento em que a demanda por projetos se diversifica, levando a novas propostas de intervenção para a arquitetura paisagística. É o período que se segue à Conferência de Estocolmo, em 1972, primeiro evento internacional a tentar harmonizar e organizar a relação entre o homem e o meio ambiente, cujos reflexos aqui no Brasil foram tão positivos que levaram à criação da Secretaria 
Especial de Meio Ambiente e ao estabelecimento de uma Política Nacional de Meio Ambiente. É quando também são definidas as regras para se estabelecer áreas de proteção ambiental e para a aplicação dos estudos de impacto ambiental e dos relatórios de impacto ao meio ambiente.

A ação dos arquitetos paisagistas, ABAP à frente, ganha em responsabilidade e também em qualidade. Os parques passam a ser, além de locais de estar e lazer, locais com fins ecológicos, nos quais as atividades humanas aconteciam em áreas agora também protegidas por uma nova legislação, que ganhava força política e apoio popular. São vários os parques que surgem nesse período: Jaraguá e Tietê, em São Paulo, Parque Setorial, em São José do Rio Preto, no interior de São Paulo e o Parque das Mangabeiras, em Belo Horizonte, estão entre os citados no livro.

É uma época na qual ocorrem renovações urbanas significativas e, no Rio de Janeiro, o projeto de Burle Marx para o largo da Carioca, como área remanescente das obras de implantação do metrô, é concebida como um grande eixo de passagem e vai se juntar a outros projetos de sua lavra, porém realizados em épocas distintas, com partidos também distintos, mas que criam uma área contínua de jardins: praça Estado da Guanabara, largo da Carioca, Estação Carioca do Metrô, jardins do prédio do BNDES e do prédio da Petrobrás, além da Estação de Bondes de Santa Teresa chegam a confundir o olhar dos desavisados, que vêem neles um espaço único, formando um conjunto de seis jardins projetados por um único paisagista, fato sem precedentes no mundo, criando, com o Convento de Santo Antônio, um cenário onde o antigo e o moderno se unem, valorizam-se e complementam-se.

Seguindo em sua análise, o texto destaca o projeto de Burle Marx para o Centro Empresarial Botafogo, que preservou as palmeiras que existiam no casarão onde funcionava a Embaixada da Argentina, mudando o projeto arquitetônico para preservá-las, sinal de um novo tempo e de uma nova visão ambiental e paisagística, cuja semente havia sido lançada com a luta pela preservação da figueira da rua Faro, no bairro do Jardim Botânico, poucos anos antes. Esse projeto, que também pode ser visto como um Pocket park, categoria criada por Robert Zion, em Nova York, em 1967, liga-se à praça Chaim Weismann, cujo projeto foi doado por Burle Marx à Associação de Moradores e Amigos de Botafogo, depois de uma amigável queda de braço entre o José Tabacow, na época militando pela AMA Botafogo, que era contra a demolição do casarão da embaixada, e Roberto, que havia sido contratado para fazer o paisagismo do prédio.

Em São Paulo, Rosa Kliass e Jorge Wilheim ganhariam o concurso de projetos para a reurbanização do vale do Anhangabaú, onde se destacou a valorização do uso do espaço pelo pedestre, tendência que se consolidaria junto dos arquitetos paisagistas e que podem ser vistos em projetos paisagísticos posteriores espalhados pelo Brasil.

Há uma citação importante nesse capítulo, sobre o projeto do Parque Moça Bonita, em Bangu, no Rio de Janeiro, projetado por Burle Marx e nunca executado. Essa poderia ser uma linha de pesquisa interessante para uma dissertação de mestrado, ou mesmo um livro, sobre os projetos de Burle Marx não-executados. 
O texto aborda a questão da participação dos arquitetos paisagistas na elaboração de planos diretores, as equipes multidisciplinares atuando cada vez mais nos projetos de paisagens urbanas, o paisagismo passando a ser visto como condicionante de relaxamento psíquico, conceito que Ebenezer Howard já defendia na virada do século 19 para o 20, visando justificar suas idéias sobre as cidades-jardins e analisa um aspecto interessante e um pouco desprezado pelos pesquisadores: o paisagismo como marca ou "imagem" empresarial. Hoje, é prática recorrente uma instituição adotar uma praça pública, financiar um projeto de restauração paisagística ou de reflorestamento. Associar o nome de uma empresa a ações ecológicas e ambientais não só passou a ser visto como um diferencial, mas também capaz de trazer grande retorno institucional. Nesse campo o Banco Safra foi praticamente um pioneiro e, nos anos 80 , foi o grande mecenas da obra paisagística de Burle Marx, na qual também se inseriam magníficos painéis. $O$ texto segue analisando o paisagismo dos loteamentos e, do geral, parte para o particular, comentando o paisagismo residencial.

O quarto capítulo se desenvolve sob a pena de Mônica Bahia Schlee e aborda o período entre 1986 e 1995, analisando os diferentes aspectos que influíram diretamente na forma das cidades. Crescimento desordenado, inchaço urbano, aumento populacional, ações imobiliárias predatórias e as buscas por alternativas para reverter algumas dessas situações e a participação dos arquitetos paisagistas nas propostas apresentadas. Da década de planejamento, nos anos 70, as décadas de 1980 e 1990 foram as décadas da implantação dos projetos.

O texto analisa a evolução ocorrida nos conceitos e nas tendências projetuais, na morfologia urbana e nos aspectos funcionais e sociais dos espaços públicos e semipúblicos. Trata a questão dos concursos públicos e das intervenções urbanas, principalmente aquelas nas quais a arquitetura da paisagem se faz mais presente. Entre os projetos analisados está o Rio-Orla, os Rio-Cidade 1, em bairros da zona sul carioca e o Rio-Cidade 2, em bairros da zona norte, o Favela-Bairro e o Parque Tom Jobim, todos no Rio de Janeiro, além de analisar projetos em São Paulo, Minas Gerais, Salvador e Recife. Avalia a produção paisagística de Burle Marx no exterior, citando o projeto feito para Kuala Lumpur.

A realização, no Rio de Janeiro, da Conferência Geral das Nações Unidas sobre o Meio Ambiente e o Desenvolvimento - Eco-92, e seus desdobramentos sobre a visão ambiental, levariam a uma nova postura por parte dos arquitetos paisagistas. A ecogênese defendida por Chacel e Luiz Emygdio, que visava, principalmente, reconstituir as condições ecológicas originais de uma determinada área aparece, além do Parque da Gleba E, na Barra da Tijuca, também em outros parques como o Bosque da Barra e o Parque Chico Mendes, no Rio; o Parque Caminhos do Mar e o da serra da Cantareira, em São Paulo, e o do Abaeté, em Salvador, são analisados nesse capítulo de forma detalhada. Nos espaços livres privados são analisados vários projetos para hotéis, fábricas, áreas livres de condomínios residenciais e outros espaços, como áreas comuns de prédios residenciais e escritórios. 
E, por fim, chegamos ao quinto capítulo, que versa sobre a arquitetura paisagística no período entre 1996 e 2006, abordando temas sobre a elaboração e a implantação de grandes parques, enfocando a construção da paisagem a partir de novos elementos arquitetônicos e novos parâmetros artísticos. Do jardim residencial, da pracinha de bairro ou do jardim integrado a um determinado prédio, o paisagismo abordado nesse capítulo abrange a dita "grande produção", que atende a situações como o paisagismo de terraços-jardins de aeroportos, projetos para orlas de represas e resorts, indo até a recuperação paisagística de áreas de entorno de monumentos tombados e de recomposição de áreas degradadas, como o depósito de rejeitos da Alumar, projeto de Eduardo Barra e Márcia Nogueira Batista. Aborda também a requalificação urbana por meio da arquitetura paisagística, a criação de espaços comunitários e vai até a Alemanha para mostrar o projeto de Burle Marx destinado a um complexo de piscinas climatizadas, conhecido como The Tropical Island, em Berlim.

Cabe frisar que os projetos de Burle Marx entre 1956 e 1964 tiveram a co-autoria de Júlio Cezar Pessolani, John Godfrey Stoddart, Fernando Tábora e Maurício Monte, e, no período entre 1964 e 1984, contou com a co-autoria de José Tabacow e Haruyoshi Ono. De 1984 até o falecimento de Roberto, em 1994, a co-autoria ficou com Haruyoshi, que permanece à frente da Burle Marx Paisagismo Ltda até hoje.

Enfim - ufa!, Temos, nesse livro, um panorama bem completo da evolução de nosso paisagismo, indo das intervenções de Maurício de Nassau em Recife e Olinda, de mestre Valentim e Glaziou no Rio de Janeiro, passando pela vasta obra de Roberto Burle Marx, aqui e no exterior, chegando-se até a produção atual, que nada fica a dever à produção de outros países, cuja tradição paisagística é bem anterior à nossa. Leitura obrigatória para estudantes, estudiosos, pesquisadores e aficionados por paisagismo. Uma coisa boa do livro é que ele só vai até o ano de 2006. O que nos faz acreditar que virá um segundo volume daqui a uns anos.

\section{Sérgio Treitler}

Arquiteto e paisagista, integrou a equipe de Roberto Burle Marx entre 1977 e 1984, é pós-graduado em Engenharia de Meio Ambiente pela UFRJ e mestrando em Arquitetura e Urbanismo pela UFF. É técnico do Iphan, onde atua na área de intervenções em jardins históricos, e possui escritório de projetos (Cache-pot Paisagismo), no qual desenvolve projetos paisagísticos para particulares. 
